\title{
Remembering Stephen McMahon, a great electrophysiologist, innovator and mentor
}

S tephen McMahon, Sherrington Professor of Physiology in the Wolfson Centre for Age-Related Diseases at King's College London, died from cancer aged 66 on 9 October 2021. He died peacefully in his home, surrounded by his family and friends.

Stephen (or Mac, as he was known) was a major figure in pain and spinal cord injury research. He was a consummate electrophysiologist, trained at University College London in the early 1980 s by one of the founding fathers of modern pain research, Professor Patrick Wall. When Mac started his own laboratory at St Thomas' Hospital Medical School in 1984, he quickly set out to publish a series of seminal papers. For example, he and his group mapped out activity-induced changes in the receptive fields of spinal cord neurons $s^{1,2}$ and were among the first to demonstrate that neurotrophins, such as nerve growth factor (NGF) and brain-derived neurotrophic factor (BDNF), can become pain mediators in the adult somatosensory system ${ }^{3-6}$. This was a major discovery that still influences pain research today. Anti-NGF antibodies are analgesic ${ }^{7}$, but their dose-limiting side effects prevented them from passing regulatory approval last year. Nevertheless, many in the field still believe in and actively pursue the strategy of targeting pathways downstream of NGF in the hope of obtaining better painkillers.

Mac had an uncanny knack for identifying promising drug targets. His team was the first to show that the enzyme chondroitinase $\mathrm{ABC}$ can be used to promote growth and functional recovery after spinal cord injury ${ }^{8}$, and his work on the role of $\mathrm{P} 2 \mathrm{X} 3$ receptors in the periphery and spinal cord $^{9,10}$ has contributed to the current development of P2X 3 and P2X2 inhibitors as treatments for chronic pain and cough.

Ultimately, though, what was perhaps most memorable and unique about Mac was his amazing originality and intellectual generosity. Those of us who were lucky enough to train with him would often try to waylay him between his official meetings accosting him in kitchens or corridors, just for the chance of a ten-minute chat about our project that would invariably make us feel energized and give us yet another great idea for the next experiment. At conferences, he would ask smart questions after almost

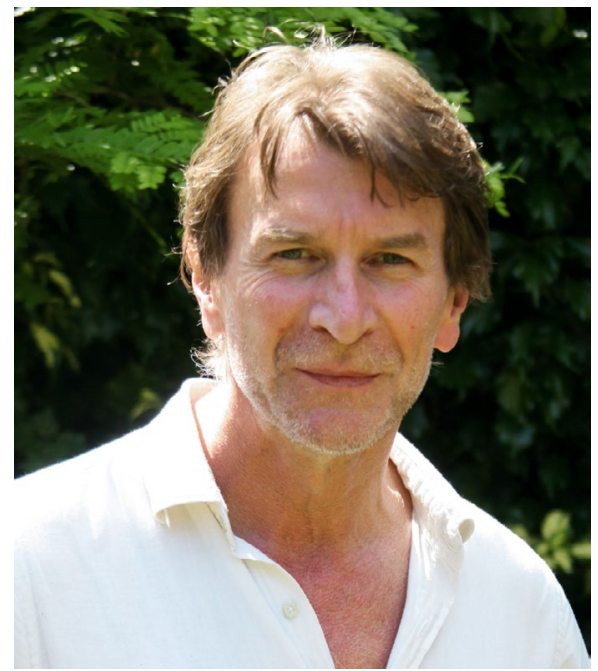

Credit: Catherine Rowlands

every talk - the kind that didn't show off or intimidate the speaker, but genuinely offered good ideas and suggestions. And if a PhD student or postdoc led the development of a new research programme in his lab, he would find a way to let them 'take it' and use it to promote their own careers, which he would then unreservedly support without jealousy or competition.

All this made Mac an absolutely outstanding mentor and collaborator. Many of the scientists he trained are now group leaders in their own right, at prestigious institutions such as the University of Oxford, Imperial College London, King's College London, the Max Delbrück Institute in Berlin and the University of British Columbia in Vancouver. Meanwhile, his collaborators often benefited from his great ability to connect people and share his scientific enthusiasm - Mac was the director of various large research networks in the United Kingdom and beyond, including the London Pain Consortium (funded by the Wellcome Trust, 2002-present) and EuroPain (funded by the European Union, 2009-2014).

For his own science, his originality and curiosity meant that he was always happy to branch out into new techniques or related research areas. Most recently, his was one of the first laboratories in the world to adapt the technique of in vivo calcium imaging for use in peripheral sensory neurons ${ }^{11-13}$. The method was particularly fascinating to him, as it can visualize the activity of large numbers of neurons at once. As someone who knew first-hand how laborious in vivo electrophysiology data are to collect, he was keen to find faster ways to gather large amounts of information on sensory neuron function, even if it had to be via the proxy measure of calcium transients.

Nevertheless, electrophysiology was and remained his first scientific love right until the end of his life. Mac was very practical - indeed, as a teenager, he did so well in his job at a vacuum cleaner repair shop in East London that the owner anointed him his chosen successor. Luckily for somatosensory research, Mac went to Leeds University instead and trained in the art of electrophysiological recordings. He knew his way around every recording rig, and rumor has it that he even wired one of his first London homes. Right until the end, he conducted his own recordings, with his last electrophysiology paper published just in August this year, in Science Translational Medicine ${ }^{14}$.

At the end, once the cancer started to progress more rapidly, he was most happy being in his 'ephys room' at work and with his family at home: his wife, Sara Hamilton, his daughter Emma and his sons Arun and Jasso. They, along with his many friends and colleagues, miss him greatly every day.

\section{Franziska Denk (iD) $ه$}

King's College London, London, UK.

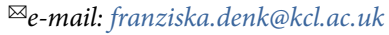

Published online: 23 December 2021 https://doi.org/10.1038/s41593-021-00987-2

\section{References}

1. Cook, A. J. et al. Dynamic receptive field plasticity in rat spinal cord dorsal horn following C-primary afferent input. Nature 325 151-153 (1987).

2. Lewin, G. R., McKintosh, E. \& McMahon, S. B. NMDA receptors and activity-dependent tuning of the receptive fields of spinal cord neurons. Nature 369, 482-485 (1994).

3. McMahon, S. B. et al. Expression and coexpression of Trk receptors in subpopulations of adult primary sensory neurons projecting to identified peripheral targets. Neuron 12, 1161-1171 (1994).

4. Crowley, C. et al. Mice lacking nerve growth factor display perinatal loss of sensory and sympathetic neurons yet develop basal forebrain cholinergic neurons. Cell 76, 1001-1011 (1994).

5. McMahon, S. B. et al. The biological effects of endogenous nerve growth factor on adult sensory neurons revealed by a trkA-IgG fusion molecule. Nat. Med. 1, 774-780 (1995). 
6. Thompson, S. W. N. et al. Brain-derived neurotrophic factor is an endogenous modulator of nociceptive responses in the spinal cord. Proc. Natl Acad. Sci. 96, 7714-7718 (1999).

7. Zhang, B. et al. Relative efficacy and safety of tanezumab for osteoarthritis: a systematic review and meta-analysis of randomized controlled trials. Clin. J. Pain 37, 914-924 (2021).

8. Bradbury, E. J. et al. Chondroitinase $\mathrm{ABC}$ promotes functional recovery after spinal cord injury. Nature 416, 636-640 (2002).
9. Cockayne, D. A. et al. Urinary bladder hyporeflexia and reduced pain-related behaviour in P2X3-deficient mice. Nature 407, 1011-1015 (2000)

10. Kaan, T. K. et al. Endogenous purinergic control of bladder activity via presynaptic $\mathrm{P} 2 \mathrm{X} 3$ and $\mathrm{P} 2 \mathrm{X} 2 / 3$ receptors in the spinal cord. J. Neurosci. 30, 4503-4507 (2010).

11. Chisholm, K. I. et al. Large scale in vivo recording of sensory neuron activity with GCaMP6. eNeuro https://doi.org/10.1523/ ENEURO.0417-17.2018 (2018).
12. Goodwin, G. et al. Examination of the contribution of Navl.7 to axonal propagation in nociceptors. Pain https://doi.org/10.1097/j. pain.0000000000002490 (2021).

13. Kucharczyk, M. W. et al. The impact of bone cancer on the peripheral encoding of mechanical pressure stimuli. Pain 161 1894-1905 (2020)

14. Jones, M. G. et al. Neuromodulation using ultra low frequency current waveform reversibly blocks axonal conduction and chronic pain. Sci. Transl. Med. 13, eabg9890 (2021). 